\title{
O Bumba Meu Boi do Maranhão, a cultura popular e o Museu Casa de Nhozinho
}

\section{Maranhão's Bumba Meu Boi, popular culture and the Casa de Nhozinho Museum}

Walter Rodrigues Marques ${ }^{1 *}$, Flor de Cássia Pereira da Silva1 ${ }^{3}$, Aline Ribeiro Casas Nova de Sousa $2^{2}$, Silvia Teresa de Jesus Pereira Dutra3 ${ }^{3}$, Hugo Leonardo Pereira Bezerra4 ${ }^{3}$, Ângela Ribeiro Casas Nova de Sousa5², Janes Claudio de Jesus Moraes6², Luis Félix de Barros Vieira Rocha72

\section{RESUMO}

O artigo versa sobre o Bumba Meu Boi e sua relação com a cultura popular do Maranhão com foco no Museu Casa de Nhozinho. Faz-se uma discussão sobre cultura popular, trazendo alguns conceitos do termo. Discute o bumba como manifestação da cultura popular maranhense e sua relação com o Museu Casa de Nhozinho. Expõe-se algumas questões como a perda da identidade do Boi (tradição ou modernidade). O artigo é conceitual e busca trazer reflexões sobre o Bumba Meu Boi no Maranhão.

Palavras-chave: Bumba Meu Boi; Cultura popular; Tradição/Modernidade.

\section{ABSTRACT}

The article deals with Bumba Meu Boi and its relationship with popular culture in Maranhão, focusing on the Casa de Nhozinho Museum. There is a discussion about popular culture, bringing some concepts of the term. It discusses bumba as a manifestation of popular culture in Maranhão and its relationship with the Casa de Nhozinho Museum. Some issues are exposed, such as the loss of the Boi's identity (tradition or modernity). The article is conceptual and seeks to bring reflections on Bumba Meu Boi in Maranhão.

Keywords: Bumba Meu Boi; Popular culture; Tradition/Modernity.

\footnotetext{
${ }^{1}$ SEDUC-MA (Secretaria de Estado da Educação do Maranhão)

*E-mail: walter.marques@ discente.ufma.br

${ }^{1}$ Instituto Estadual de Educação, Ciência e Tecnologia - IEMA, Bacabeira.

${ }^{2}$ SEMED (Secretaria Municipal de Educação) de Matões do Norte

3 SEMED-São Luís (Secretaria Municipal de Educação de São Luís)
} 


\section{INTRODUÇÃO}

O que é cultura popular? Para Arantes (1983), é a manifestação das populações que não está sistematizada como 'cultura'. Portanto, 'cultura popular' é o contrário de 'cultura'. A ideia que se tem ou se tinha (?) da cultura popular é a “de um não-saber" que, em oposição à 'cultura', significa quem tem cultura e quem não tem, ou seja, o que é considerado cultura e o que não é. Na definição do que é e do que não é, há uma clara divisão de classes - os que detém o poder de definir e os que devem aceitar. Bourdieu elaborou seu pensamento sobre capital cultural baseado na divisão de classe. É não se pode esquecer como o Bumba Meu Boi era considerado até meados da década de 1970, o qual não tinha autorização nem de ultrapassar a linha imaginária (mas também simbólica do bairro do João Paulo) que separava a elite ludovicense dos outros.

O pensamento europeu se consolidou hegemonicamente como símbolo de "civilização", quem não professasse tal comportamento, não era civilizado. Boaventura de Sousa Santos elabora uma explicação sobre isso ilustrando a demarcação das linhas abissais do pensamento onde existe o lado de cá e o lada do lá - o mundo civilizado e os bestializados, respectivamente. Partindo da forma como Bourdieu elaborou sua tese sobre capital cultural a partir de suas vivências na Argélia, traçando um perfil de classe para definir o gosto, faz-se analogia com a divisão da arte em maior e menor. As artes plásticas, especialmente a pintura, a escultura e a arquitetura, foram chamadas, na Renascença, de "belas-artes", enquanto as outras atividades artísticas como o artesanato, a ourivesaria, foram relegados ao lugar de arte menor, do povo, da cultura popular.

O termo cultura popular está imbricado em múltiplos significados, portanto, contraditório. A cultura é um conjunto de diferentes recursos, coexistindo sempre numa relação de troca entre o dominado e o dominante, a aldeia e a metrópole (THOMPSON, 1998), o lada de cá e o lado de lá (SANTOS, 2007).

A sociedade como invenção da cultura (WAGNER, 2012) perpassa por construções sociais de realidades discursivas, linguagem e conhecimento, institucionalização, ideologia, níveis de socialização com estrutura social, subjetividade, identidade (BERGER, 2014). A cultura também constrói a história, produção de saberes e verdades, sistematização e/ou regularidades discursivas e da ordem do discurso (FOUCAULT, 2014). 
A Antropologia, a partir da visão estrutural buscou identificar os traços culturais das várias sociedades espalhadas pelo planeta e pode traçar com certa margem de acerto, como as sociedades, outrora chamadas de primitivas concebiam as relações intra e interpessoais e grupais. Com isso, os antropólogos traçaram perfis sobre a ideia de cultura (EAGLETON, 2011). Nesse bojo, vale remeter ao processo civilizador (ELIAS, 1980), a invenção da cultura (WAGNER, 2012), a sociedade contra o Estado (CLASTRES, 2013), o saber local (GEERTZ, 2014), o local da cultura (BHABHA, 2013), a cultura no plural (CERTEAU, 2013). E mais recentemente, as faces contemporâneas da cultura popular (FARIAS; MIRA, 2014), as culturas híbridas (CANCLINI, 2013), a identidade cultural na pós-modernidade (HALL, 2006).

A nova antropologia, ou antropologia interpretativa, hermenêutica, vem dá um sentido mais dinâmico das relações culturais, ou seja, um olhar mais atento e profundo sobre a interpretação das culturas (GEERTZ, 2015). O discurso sobre a cultura é pertinente na medida em que é a cultura que define o que e como a sociedade deve guiarse. A sociedade normatiza a forma como os indivíduos devem se comportar. Portanto, dita as regras de como a humanidade deve lidar com seu passado, sistematizando o local de guarda dos artefatos materiais, ou seja, a cultura material assim como a representação da cultura imaterial, elegendo para essa guarda, o local o qual se denominará - museu.

O Museu Casa de Nhozinho ${ }^{3}$ tem como características, referenciar, estimular e divulgar aspectos da cultura popular maranhense no tocante à vida cotidiana e o fazer de seu povo, abrindo espaços para artefatos das culturas indígenas, artesanato, brinquedos populares, reciclados e de coleções de pesquisadores maranhenses. Este revela um ambiente contendo variadas técnicas de produção da cultura popular do maranhense seus usos e costumes, cujo acervo dispõe de artesanatos ligados ao cotidiano e a cultura do povo. O acervo do museu foi fruto de doações, possuindo além das obras do próprio homenageado, outras de anônimos artesãos, além de coleções adjuntas como as de Vítor Gonçalves, João do Farol, Beto Bittencourt, artesanato e Manufaturas, elementos voltados para a pesca e embarcações, ervas medicinais, artefatos de metais miniaturas, artefatos de materiais reciclados, artefatos em tecido e fibras vegetais, elementos da cultura indígena, brinquedos populares, exposição de variados tipos de louças, com destaque para a

\footnotetext{
${ }^{3}$ A descrição do Museu Casa de Nhozinho foi cedida pelo estagiário da casa, Luís Fernando Lima Figueredo. Serão feitas adaptações, mas a ideia primária será mantida.
} 
produção das Anas, grupo de artesãs do município de Mirinzal, casa da farinha e galeria do cofo. $\mathrm{O}$ acervo de Nhozinho, considerada a principal coleção, fica no último andar do prédio, este é composto por fotos, textos que fazem a composição informativa, além das peças, miniaturas de rendeiras, caixinhas de segredo, as famosas rodas de bumba boi, além de personagens isolados e de parte de sua oficina, e da cadeira confeccionada por ele.

O museu não possui nenhum registro e nenhum levantamento do total de obras expostas, o que se sabe é que são 21 salas ao todo, sendo 17 salas de exposições abertas ao público:

Tabela 1 - Espaços do Museu Casa de Nhozinho

\begin{tabular}{|c|c|}
\hline 1 & Pavilhão Terra \\
\hline 2 & Pavilhão Água \\
\hline 3 & Ervas Medicinais \\
\hline 4 & Vitrine Nhozinho \\
\hline 5 & Miniaturas \\
\hline 6 & Coleções adjuntas \\
\hline 7 & Coleção Beto Bittencourt \\
\hline 8 & Brinquedos populares \\
\hline 9 & Artefatos de Metais \\
\hline 10 & Artefatos de materiais reciclados \\
\hline 11 & Artefatos em tecido e fibra vegetais \\
\hline 12 & Cultura indígena \\
\hline 13 & Exposição Louça Bonita \\
\hline 14 & Sala da Comissão Maranhense de Folclore \\
\hline 15 & Reserva técnica \\
\hline 16 & Administração \\
\hline 17 & Sala de áudio \\
\hline 18 & Galeria do cofo \\
\hline 19 & Casa da Farinha \\
\hline 20 & Forno de barro \\
\hline 21 & Modelos de casas populares (taipa, adobe e palha) \\
\hline
\end{tabular}

Fonte: Cedido pelo estagiário Luís Fernando

A casa, concluída em 1999 com recursos do governo estadual, foi o resultado de um projeto elaborado pela equipe do Centro de Cultura Popular Domingos Vieira Filho, 
da Secretaria de Estado da Cultura, que nesta área atua sempre com o respaldo da Comissão Maranhense de Folclore uma organização não governamental que congrega especialistas em cultura popular e representantes dos grupos que praticam e preservam estas manifestações.

A Casa de Nhozinho está ligada à Superintendência de Cultura Popular do Maranhão e foi inaugurada no dia 02 de julho de 2002 na Rua Portugal, nº185, Praia Grande em São Luís. Encontra-se localizado em um sobrado com partido interno típico do período colonial, mas com influências neoclássicas na fachada, que por sua vez é revestida com uma barra de azulejos franceses. Atualmente sob a direção da historiadora Reinilda Oliveira e doze monitores.

O nome Casa de Nhozinho é uma homenagem ao grande artesão maranhense Antônio Bruno Nogueira, conhecido por Nhozinho, que foi um escultor de personagens, em madeira de buriti, de brincantes das festas de bumba-meu-boi, que marcou sua passagem pelo reconhecido valor artístico de suas esculturas. Notabilizou-se também em virtude de que durante a maior parte de sua laboriosa existência padeceu de uma doença degenerativa que lhe deformava as mãos e os pés e é sabido que para trabalhar nas suas esculturas necessitava de muita habilidade para utilizar suas ferramentas.

O espaço apresenta uma mostra das técnicas de produção da cultura material do maranhense no seu dia a dia que passa pela arte indígena, peças de cerâmica, utensílios de pesca artesanal, miniaturas e tipos populares até artefatos de grande porte, como veículos de locomoção, e construção civil.

No andar térreo, no Salão Água, encontra-se o acervo diretamente relacionado a rios e mar como canoas e redes de pesca, enquanto o Salão Terra retrata a relação do homem com a terra, configurada na agricultura e na construção de sua moradia. Nesse espaço foi montado, ainda, o Pátio Verde, que evidencia a relação homem/natureza, com a decoração dos entornos da casa, como pátios e jardins, com plantas e ervas medicinais dando boas-vindas ao visitante. No primeiro andar, o visitante tem acesso ao Pavilhão Fogo, onde está exposto todo o acervo de artesanato como brinquedos populares, miniaturas, reciclados, tecidos e as coleções adjuntas de Nhozinho, Domingos Vieira Filho, José Cupertino, Vítor Gonçalves, João do Farol e Beto Bittencourt, além da cultura material indígena e objetos feitos em metais. O segundo pavimento, que dá uma segunda opção de entrada pela Rua de Nazaré, foi denominado Pavilhão Ar. Nele o visitante tem aceso à Galeria do Cofo, destinada a exposições temporárias; à parte administrativa do 
Centro de Cultura Popular Domingos Vieira Filho (CCPDVF); à Sala da Comissão Maranhense de Folclore, a um atelier de artesanato, onde o artesão Abel Teixeira confecciona "in loco" caretas de Cazumba; ao gabinete de conservação e restauro e ao pátio grande com réplicas de casa de farinha e forno de barro. Se o visitante optar pela entrada dos fundos da Casa, vai iniciar a sua incursão pela cultura popular maranhense conhecendo alguns ambientes da zona rural logo na entrada do pátio. Ali foram construídos um refeitório, um dormitório, uma capelinha, uma loja e uma quitanda, com diferentes tipos de materiais de construção utilizados pelo homem do interior.

A Casa de Nhozinho nos mostra a importância de preservar espaços culturais que possibilitam as pessoas a oportunidade de conhecer, apreciar e valorizar a cultura do Estado, espaço este que se preserva a cultura popular maranhense, os saberes das manifestações populares, enquanto elemento de ligação entre o passado e o futuro, o que possibilitou abrir olhares para elementos tão comuns ao maranhense, fazendo com que outros valorizem práticas e costumes dessa gente.

\section{BUMBA MEU BOI}

A partir das leituras obrigatórias para cumprimento de estágio, selecionou-se textos relacionados ao Bumba Meu Boi. Destaca-se em sequência o pensamento dos autores, aprofundando-se no tópico relacionado ao Boi Costa-de-Mão. 'Rapaziada' reflete o traço de masculinidade da 'brincadeira' de bumba-meu-boi, que era coisa de homem e não de mulher. Os papéis de mulher eram feitos por homens, o que para alguns brincantes ficava mais engraçado que se fosse feito por uma mulher e, isso foi internalizado pelas mulheres que, até pouco tempo, concordavam com essa postura de auto discriminação. Isso começa a sofrer alteração a partir da década de 1970, quando a mulher passa a assumir outros papéis que não apenas de "mutucas", mas

\footnotetext{
Por outro lado, há registros na memória de antigos brincantes da lembrança da existência, tanto em São Luís como em municípios do interior do Estado, de grupo de boi só de mulheres, organizados por elas, chegando a ganhar pique, vencendo até mesmo famosos concursos, como os da "Escola Técnica", no final da década de 40 , início da década de 50, mas quase sempre estava por trás dessa iniciativa a intenção de suprir a falta do tradicional conjunto masculino (CARVALHO, 1996, p. 41).
}

Michol Carvalho aponta as mudanças dos tempos e com isso, espaço para a mulher em todos os papéis dantes ocupados apenas por homens. Ainda não é um lugar definido, 
uma vez que esse estar no lugar do homem, no papel que a ele sempre foi destinado, se dá, muitas vezes, por falta de homens, por variados motivos. Mas reforça que a mulher está sim ocupando esses lugares de atuação.

Carlos de Lima apresenta o enredo do bumba meu boi com as etapas do auto e, ressalta situações e/ou ocasiões em que algumas etapas são suprimidas, ou seja, nem sempre todas as etapas são apresentadas, o que depende de muitas variáveis.

Guarnicê - primeiro momento de reunião, agrupamento, preparação para o início da brincadeira;

Lá vai - é uma toada que avisa àqueles que esperam o boi e anuncia o local da apresentação;

Licença ou chegou - é o pedido de permissão para apresentação do grupo e seu novilho;

Saudação - toadas de louvação ao boi e ao dono da casa. A partir desse instante tem-se, então, o desenvolvimento do auto propriamente dito, que finda com as toadas do urrou;

Urrou - o momento de alegria e confraternização geral em torno do boi, novamente vivo;

Despedida - corresponde ao final da apresentação e à retirada do grupo, tendo por tema sentimentos de adeus e de saudade que o boi deixa e leva, ao se afastar, cantando e sempre prometendo voltar (LIMA, 2003, p. 42-43).

Em seguida destaca os personagens do bumba-meu-boi do Maranhão.

Boi - personagem central do enredo, é confeccionado em diferentes tamanhos, com armação de varas, e entrecasca de buriti (árvore encontradiça em todo o Estado) coberta pelo "couro" de veludo, ricamente bordado à mão com miçangas, paetês e canutilhos, utilizando como tema os mais originais e interessantes motivos. [...].

Amo - é o dono da fazenda, da festa e do boi. Personifica o senhor, o latifundiário. Veste a roupa mais rica e caprichada e usa o apito para dirigir o conjunto e o auto.

Rapaz - vaqueiro e empregado mais próximo do amo.

Pai Francisco (Chico) - vaqueiro que, na estória, faz o papel de vilão; hilariante, fica a seu cargo a parte humorística da representação e sua atuação provoca sempre o riso do público.

Mãe Catirina - mulher do Pai Francisco, pivô da questão-tema. Sempre é um homem vestido de mulher e sua participação completa a farsa.

Vaqueiros e rajados - compõem o cordão e representam empregados e moradores da fazenda. [...].

Doutores, pajés, curadores - personagens igualmente engraçados que compõem a pantomima.

Índios e índias - responsáveis pela perseguição e prisão do Pai Francisco. Vestem roupas cobertas de penas de ema e são em número variável.

Caboclos de pena - também em número variável, são principalmente encontrados nos "Bois de Matraca". [...].

Burrinha - personagem comum em todo o Nordeste. [...].

Cazumbá - em número variado, é encontrado nos bois da Baixada. [...].

Caipora - aparece em alguns grupos (LIMA, 2003, p. 43, grifo nosso). 
Segundo Carlos de Lima existem três estilos básicos de bumba-meu-boi no Maranhão, que são: o Sotaque de Matraca ou da Ilha, de Zabumba e de Orquestra. Classifica Pindaré e Cururupu como sub-sotaques ou variantes de estilos/regional.

\begin{abstract}
Sotaque de matraca ou da ilha - É o grupo mais aberto ao grande público, cujo número de brincantes não tem limite; qualquer um pode integrar-se a ele; sua percussão apresenta os pandeirões e as matracas (tabuínhas batidas umas contra as outras) de grande efeito rítmico. É elemento importante no entusiasmo de brincantes e assistentes e tão excitante o clímax que provoca quanto à fervura no frevo pernambucano.

Sotaque de zabumba - caracteriza-se pela marcante presença dos grandes tambores; tem ritmo fortemente africano.

Sotaque de orquestra - usa instrumentos de corda e de sopro como banjo, pistom clarinete, etc. e percussão mais suave do que os de matraca e zabumba. Há ainda outras variantes de estilos, peculiares a casa região, que podemos considerar sub-sotaques, como, entre outros, os de:

Sotaque de Pindaré - que se distingue por um toque mais leve e suave, tanto dos pandeiros como das matracas, e um ritmo mais lento.

Sotaque de Cururupu - diferente dos demais pelo jeito especial de marcar o ritmo com os chamados "pandeiros de costa de mão" (LIMA, 2003, p. 44).
\end{abstract}

Baseada em pesquisa documental de fotografias de Gautherot ${ }^{4}$ no Instituto Moreira Salles, Martins (2015), constatou a representação de apenas três sotaques: matraca, zabumba e baixada. Martins relata que na década de 1940 já havia vários sotaques, embora pouco conhecidos, mas em 1968, Carlos de Lima em "Bumba-meuboi" só cita três sotaques. Em 1980, José de Ribamar Reis, continua com apenas esses três sotaques como principais, mas já considera que existem dois estilos independentes, “os Bois de Pindaré e o Boi de Cururupu”. Em fins da década de 1980, Michol Carvalho compreende a existência dos sotaques de matraca, zabumba, orquestra e Pindaré.

$\mathrm{Na}$ atualidade, se faz referência a cinco principais sotaques de bumba-meu-boi no Maranhão. Como feito por Carlos de Lima nos fins da década de 1990, classificando uma manifestação como de menor relevância, como "sub-", é possível que quando se faz a referência a cinco principais sotaques, o mesmo equívoco se esteja cometendo, ao classificar a atuação do bumba-meu-boi hoje. Ou, isso é apenas parte do processo de atualização dos fazeres da humanidade.

Abmalena Sanches analisa o batismo no "grupo de bumba-meu-boi da Madre de Deus, o Capricho do Povo, sotaque de matraca ou da ilha" (2003, p. 45). É comum o batismo da maioria dos grupos, em São Luís, acontecer em 23 de junho que é a véspera

\footnotetext{
${ }^{4}$ As fotografias não apresentam data, mas por ocasião do Movimento Folclórico das décadas de 40-50 o fotógrafo viaja a São Luís em 1948 e registra o bumba-meu-boi, supõe-se que seja deste ano.
} 
de São João. Geralmente os bois são organizados em promessa a São João. O batismo é um ritual que já está na prática dos brincantes de bumba-meu-boi e concordando com Van Gennep (1977, p. 32), “... consiste em assegurar uma transformação do estado ou a passagem de uma sociedade mágico-religiosa ou profana para outra...". o batismo dá ao boi a condição de sair do paganismo para a liberdade do estado de pureza e proteção (SANCHES, 2003, p. 46).

Há aqui, uma análise do batismo do boi com o batismo cristão, a proteção é a mesma. Há um jogo entre o sagrado e o profano muito forte nessa relação do boi com o mundo. $\mathrm{O}$ batismo se inicia geralmente às 22 horas e a cerimônia dura em torno de 1 hora. São proferidas pelo padrinho as seguintes palavras: "Eu te batizo Capricho do Povo em nome de Deus. Que São João, São Pedro e São Marçal te proteja em todas as Campinas que tu vadiar"(SANCHES, 2003, p. 48). A partir do batismo o boi está prontopara sair de casa e ganhar o mundo para brincar, vadiar etc.

Apresentam-se dicotomias como sagrado e profano, doméstico e público, nos ritos de passagem do antes e depois do batismo do boi. A autora destaca que a maioria dos grupos de boi em São Luís fazem a primeira apresentação no bairro que abriga o boi.

Segundo Canjão (2003, p. 61) "O bumba-meu-boi do Maranhão é uma manifestação que articula símbolos e significados, sentidos que se transmite através dos tempos e que vão constituindo e reconstituindo a história do povo que a produz". O discurso gira em torno da identidade, do pertencimento, da herança. Utiliza como metáfora a árvore, esta que precisa ter raiz forte para se tornar formosa, dar bons frutos. É de pequena que a criança experimenta a tradição. O estudo é sobre o boi da Maioba que, como testemunha viva tem Mãe Rita de 104 anos por ocasião da composição, por volta do ano 2000. Portanto, o Boi da Maioba é centenário. Ester Marques (2003) tece um discurso sobre a dicotomia entre tradição e modernidade.

\footnotetext{
Não se pode confundir tradição com antiguidade ou modernidade com a atualidade porque nem a tradição é necessariamente uma realidade antiga, nem a modernidade é uma realidade recente, atual. Dessa forma, enquanto antiguidade e atualidade são recortes cronológicos da história, a tradição e a modernidade são representações do mundo que se encontram em qualquer época e que coexistem em todas as culturas. [...]. Consequentemente, a tradição e a modernidade são termos que coabitam dialeticamente, em qualquer fenômeno cultural, em permanente tensão, segundo a perspectiva históricosocial adotada. (MARQUES, 2003, p. 50).
}

Segundo Ester Marques (2003), a dialética convive com a constituição da dinâmica cultural do bumba-meu-boi em três aspectos: o primeiro diz respeito às 
referências históricas e simbólicas, distintas e variáveis, dependendo do aqui e agora dos grupos, sempre substituindo o valor de culto pelo valor de exposição e visibilidade, de tradição e modernidade; no segundo aspecto, a tradição tem fundamento no enraizamento comunitário no contexto cultural do bumba-meu-boi, vivido como memória coletiva, com espaço e tempo sagrados, e a modernidade funciona, dicotomicamente, como locais de experimentações sociais, estéticos e culturais com o mundo público e o mundo privado, respectivamente, da rua e de casa; no terceiro aspecto, tradição se vincula a originalidade, singularidade e identidade, portanto, sua autenticidade. Já a modernidade, vincula-se à serialização, homogeneização, standardização, dessacralizando o processo profano do folguedo, construindo ou constituindo-se os sentidos transitórios e midiáticos sempre que novas experimentações se fazem. Ainda, em dicotomias, a tradição e a modernidade aparecem como a cultura para ser e a cultura para ter.

Portanto, ser tradicional e ser moderno não desvincula o bumba-meu-boi de sua história, das perspectivas culturais, mas o enquadra em um contexto próprio e dinâmica única que só reforça a sua singularidade. Sobre a atualização cultural, sobre formar o folguedo simplesmente para agradar ao momento atual, sem preservar características originais e bases culturais relevantes, Ester Marques (2003) chama a atenção para esse processo desequilibrado do fazer/montar.

\footnotetext{
Esse desequilíbrio decorre de alguns problemas. Um deles é a aceleração da atualização cultural que faz com que alguns grupos privilegiem a mudança dos ritmos, da musicalidade, dos instrumentos, do vestuário e dos adereços, sem qualquer referência à experiência artística/ritualística do folguedo ou sem qualquer definição estética local. É uma aceleração que tem a ver diretamente com o fenômeno de esteticização da experiência, isto é, com o exacerbamento de experimentações estéticas, voltada para a fugacidade e efemeridade, sem qualquer vinculação com o enraizamento vital originário do bumba-meu-boi (MARQUES, 2003, p. 53).
}

A tendência à atualização cultural coloca o bumba-meu-boi num processo de assimilação que nada tem a ver com o folguedo. Elementos como índias seminuas ao estilo: É o Tchan, em busca de plateia é uma das várias incursões sobre o bumba-meuboi que muito distante está da versão do folguedo e seu auto.

De acordo com Cavalcanti (2003) a discussão se dá pela via da tradição e modernidade, de perdas e ganhos na evolução dos dias da cultura popular. Apresenta a ideia de desconstrução das tradições, uma vez que é uma invenção de intelectuais. 
Mudanças e tendências percebidas como problemáticas perpassam, entretanto, essa diversidade. Sumario rapidamente alguns dos aspectos arrolados pelos palestrantes: alterações no calendário tradicional, no ciclo e na estrutura da brincadeira; transformações na indumentária; transformação da brincadeira em atração e show para os visitantes; estilização 'carnavalesca' dos figurinos; priorização das toadas anuais em função do mercado fonográfico e abandono da seqüência tradicional de toadas do 'guarnecer' à 'despedida'; não encenação do auto e tendência à apresentação como conjuntos musicais e coreográficos de toadas (CAVALCANTI, 2003, p.59).

Os bois do Maranhão lidam de forma diferente com a tradição, cada sotaque e cada grupo dentro de cada sotaque, organiza as etapas, as apresentações e o que é relevante para o momento.

\section{CONSIDERAÇÕES FINAIS}

Falar do Bumba Meu Boi é um exercício que requer muito atenção, tendo em vista que muito já se disse sobre o folguedo. Portanto, melhor é se deleitar na magia do Boi, nos sonhos e cores, na tradição assim como na modernidade.

Inserir elementos no enredo requer coragem, pois corre-se o risco de descaracterização da brincadeira. Elementos como os índios e índias, personagens que para muitos são vistos como um elemento desnecessário e para outros já faz a alegria do público. Ouve-se que a ida ao arraiá é para ver os índios e índias malhadas, corpo de academia. E é isso que os tradicionais consideram um perigo.

Os bois de orquestra fazem o espetáculo esplendoroso, já os bois de sotaque de Costa de Mão, por exemplo, são mais simples, pautados na tradição. 


\section{REFERÊNCIAS}

ARANTES, Antonio Augusto. O que é cultura popular. São Paulo, Brasiliense, 1981. 83 p. (Primeiros Passos, n. 36).

BERGER, Peter L. A construção social da realidade: tratado de sociologia do conhecimento. 36. ed. - Trad. Floriano de Souza Fernandes. Petrópolis, Vozes, 2014.

BHABHA, Homi K. O local da cultura. Trad. Myriam Ávila, Eliana Lourenço de Lima Reis, Gláucia Renate Gonçalves. - 2. ed. - Belo Horizonte: Editora UFMG, 2013. - (Humanitas).

BOURDIEU, Pierre. A economia das trocas simbólicas. 7. Ed. - São Paulo: Perspectiva, 2011. - (Coleção estudos; 20/ dirigida por J. Guinsburg).

CANCLINI, Nestor Garcia. Culturas híbridas: estratégias para entrar e sair da modernidade. Trad. Heloísa Pezza Cintrão; Ana Regina Lessa. 4. ed. - 6. reimpr. - São Paulo: Editora da Universidade de São Paulo, 2013. - (Ensaios Latino-Americanos, 1).

CANJÃO, Isanda. O lugar da memória no Bumba-Meu-Boi. In: NUNES, Izaurina Maria de Azevedo (org.). Olhar, memória e reflexões sobre a gente do Maranhão. São Luís: Comissão Maranhense de Folclore, 2003.

CARVALHO, Maria Michol Pinho de. As mulheres no Bumba-Meu-Boi: saindo detrás das cortinhas. In: NUNES, Izaurina Maria de Azevedo (org.). Olhar, memória e reflexões sobre a gente do Maranhão. - São Luís: Comissão Maranhense de Folclore, 2003.

CARVALHO, Maria Michol Pinho de. As mulheres no bumba-meu-boi. Boletim da Comissão Maranhense de Folclore, São Luís, n.05, jun. 1996. Disponível em: http://www.cmfolclore.ufma.br/arquivos/4f56733221ce61470a012f5b55f55c97.pdf.

Acesso em: 07 dez. 2021.

CLASTRES, Pierre. A sociedade contra o Estado: pesquisas de antropologia política. Trad. Theo Santiago. Edição Cosac Naify Portátil. - São Paulo: Cosac Naify, 2013.

CAVALCANTI, Maria Laura. O Bumba-Meu-Boi do Maranhão: apreciação estética. In: NUNES, Izaurina Maria de Azevedo (org.). Olhar, memória e reflexões sobre a gente do Maranhão. - São Luís: Comissão Maranhense de Folclore, 2003.

DEWEY, John. Arte como experiência. Trad. Vera Ribeiro. - São Paulo: Martins Fontes, 2010. - (Coleção Todas as artes).

FARIAS, Edson Silva de; MIRA, Maria Celeste (Orgs.). Faces contemporâneas da cultura popular. Jundiaí, Paco Editorial, 2014.

FOUCAULT, Michel. A ordem do discurso: aula inaugural no Collège de France, pronunciada em 2 de dezembro de 1970. Trad. Laura Fraga de Almeida Sampaio. - 24. ed. - São Paulo: Edições Loyola, 2014. - (Leituras filosóficas). 
GEERTZ, Clifford. O saber local: novos ensaios em antropologia interpretativa. Trad. Vera Joscelyne. - 14. ed. - Petrópolis, RJ: Vozes, 2014. - (Antropologia).

HALL, Stuart. A identidade cultural na pós-modernidade. Trad. Tomaz Tadeu da Silva; Guacira Lopes Louro. - 11. ed. - Rio de Janeiro: DP\&A, 2006.

LIMA, Carlos Orlando de. O universo do Bumba-Meu-Boi do Maranhão. In: NUNES, Izaurina Maria de Azevedo (org.). Olhar, memória e reflexões sobre a gente do Maranhão. - São Luís: Comissão Maranhense de Folclore, 2003.

MARQUES, Francisca Ester de Sá. Tradição e modernidade no Bumba-Meu-Boi. In: NUNES, Izaurina Maria de Azevedo (org.). Olhar, memória e reflexões sobre a gente do Maranhão. - São Luís: Comissão Maranhense de Folclore, 2003.

SANCHES, Abmalena. A passagem da casa para a rua: o ritual do batismo no BumbaMeu-Boi. In: NUNES, Izaurina Maria de Azevedo (org.). Olhar, memória e reflexões sobre a gente do Maranhão. - São Luís: Comissão Maranhense de Folclore, 2003.

SANTOS, Boaventura de Sousa. Para além do Pensamento Abissal: das linhas globais a uma ecologia de saberes. In: Novos Estudos CEBRAP, n. 79, nov, 2007, p. 71-94.

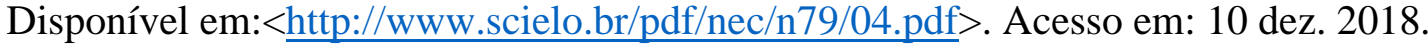

SOUZA, Ricardo Luiz de. Processo civilizador, poder e sociedade: introdução ao pensamento de Norbert Elias. - 1. ed. - Curitiba: CRV, 2014.

THOMPSON, E. P. Costumes em comum. São Paulo: Companhia das Letras, 1998.

WAGNER, Roy. A invenção da cultura. Trad. Marcela Coelho de Souza, Alexandre Morales. - 1. ed.- Cosac Naify Portátil. - São Paulo: Cosac Naify, 2012. 